\title{
Character of Frontier Orbitals of Antiviral Drugs: Candidate Drugs against Covid-19
}

\author{
Yoshihiro Mizukami \\ Faculty of Education, Shiga University, Otsu, Japan \\ Email:mizukami@edu.shiga-u.ac.jp
}

How to cite this paper: Mizukami, Y. (2020) Character of Frontier Orbitals of Antiviral Drugs: Candidate Drugs against Covid-19. Open Journal of Physical Chemistry, 10, 158-165.

https://doi.org/10.4236/ojpc.2020.103009

Received: June 4, 2020

Accepted: July 31, 2020

Published: August 3, 2020

Copyright (c) 2020 by author(s) and Scientific Research Publishing Inc. This work is licensed under the Creative Commons Attribution International License (CC BY 4.0).

http://creativecommons.org/licenses/by/4.0/

(c) (i) Open Access

\begin{abstract}
We performed density functional theory (DFT) calculations for ribonucleotides and active triphosphate metabolites of candidate drugs against Coronavirus disease 2019 (Covid-19). Frontier orbitals (highest occupied molecular orbital and lowest unoccupied molecular orbital) at optimized structure of each molecule were obtained. T-705RTP (active triphosphate metabolite of favipiravir) and cytidine triphosphate (CTP) have similar shapes of frontier orbitals. We also obtained similar shapes of frontier orbitals among dihydroxy GS-441524 triphosphate (GS-441524 is an active triphosphate metabolite of remdesivir) and adenosine triphosphate (ATP). From a theoretical viewpoint, we suggest T-705RTP is a CTP analogue and dihydroxy GS-441524 triphosphate is an ATP analogue.
\end{abstract}

\section{Keywords}

Covid-19, Antiviral Drugs, Frontier Orbitals, Ribonucleotides

\section{Introduction}

Corona Virus Disease 2019 (COVID-19) caused by a novel coronavirus (SARSCoV-2) [1] has become a pandemic worldwide. This outbreak of novel coronavirus has infected more than ten millions of humans leading to several hundred thousand deaths worldwide. Favipiravir $\left(\right.$ Avigan $\left.^{\circ}\right)$ and remdesivir are candidate drugs against Covid-19. Such antiviral drugs may inhibit the coronavirus replication/transcription mechanism [2]. Favipiravir (T-705) is an experimental antiviral drug developed by Toyama Chemical Co., Ltd., Japan which is active against RNA viruses and an effective treatment for influenza viruses, West Nile virus, yellow fever virus, and more [3]. The chemical formula of favipiravir (T-705) is shown in Figure 1(a). It can be converted into T-705 ribosyl triphosphate (T-705RTP), which is a potent inhibitor of influenza viral polymerase [4]. 
The chemical formula of T-705RTP is shown in Figure 1(b). Remdesivir is an adenosine analogue that disrupts the activity of viral RNA-dependent RNA-polymerases (RdRp). Remdesivir, developed by Gilead Sciences, is a therapeutic agent for the Ebola virus disease [5] and other single-stranded RNA viruses. The chemical formula of remdesivir is shown in Figure 1(c). Remdesivir converts to GS-441524 triphosphate (Figure 1(d)), which provides potent anti-virus activity. Both favipiravir and remdesivir are thought to be candidate drugs against Covid-19 [6] [7]. It is urgent to find therapies against Covid-19. Computer-aided drug design helps to identify a drug to combat the coronavirus [8]. Our method is a little different from the usual docking approach. Our approach is to make theoretical calculations of electronic states for antiviral drugs, especially focusing on frontier orbitals. The term frontier orbitals include both the highest occupied molecular orbital (HOMO) and the lowest unoccupied molecular orbital (LUMO). Frontier orbitals play important roles in molecular interactions and chemical reactivity [9]. Investigation of the characteristics and patterns of frontier orbitals is useful to understand various properties of molecules. We studied the toxicities of dioxins and classified frontier orbital patterns by statistical analysis [10]. To develop antiviral drugs, a tentative study was<smiles>NC(=O)c1nc(F)cnc1O</smiles>

(a)<smiles>CCC(CC)COC(=O)C(C)NP(=O)(OCC(O)OC(C#N)(c1ccc2c(N)ncnn12)C(C)O)Oc1ccccc1</smiles>

(c)

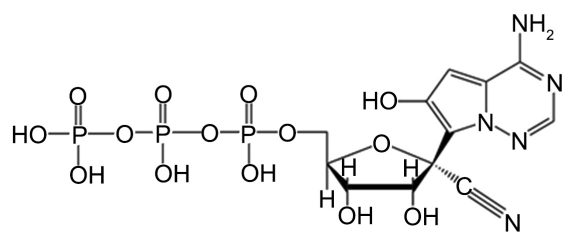

(e)<smiles>NC(=O)c1nc(F)cn(C2OC(COP(=O)(O)OP(=O)(O)OP(=O)(O)O)C(O)C2O)c1=O</smiles>

(b)<smiles>N#CC(O)(COP(=O)(O)O)C(O)(C#N)C(O)OCOP(=O)(O)OP(=O)(O)OP(=O)(O)O</smiles>

(d)

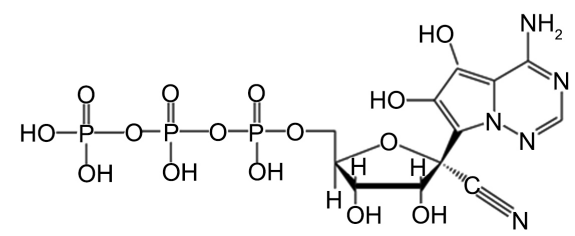

(f)

Figure 1. (a) Favipiravir (Avigan ${ }^{\circledR}$ ) (also known as T-705) (b) T-705RTP. Active triphosphate metabolite of T-705 (c) Remdesivir (d) GS-441524 triphosphate. Active triphosphate metabolite of remdesivir. (e) hydroxy GS-441524 triphosphate. (f) dihydroxy GS-441524 triphosphate. 
performed on the Ebola virus disease [11]. Here, we investigated the frontier orbitals of nucleotide analogues of favipiravir and remdesivir and compared them with the frontier orbitals of nucleotides.

\section{Method}

Density functional theory (DFT) calculations at the B3LYP/6-31G(d) level were performed to obtain the optimized structures of nucleotides, T-705RTP and GS-441524. DFT is one of the theoretical methods to calculate the energy and other properties of atoms and molecules with high accuracy from the electron density distribution. The calculated nucleotides include adenosine triphosphate (ATP), cytidine triphosphate (CTP), guanosine triphosphate (GTP), and uridine triphosphate (UTP). We also performed DFT calculations to obtain the optimized structures of hydroxy remdesivir triphosphate and dihydroxy remdesivir triphosphate, which are shown in Figure 1(e), Figure 1(f). DFT calculations were performed using the Gaussian 09 program [12]. Orbital is a useful concept in chemistry and physics. Especially, molecular orbitals provide a natural description of various properties of molecules. Although the concept of orbital originates from a single configuration like Hartree-Fock (HF) theory, DFT theory differs from a single configuration. However, DFT shares an orbital picture with Kohn-Sham (KS) orbitals. Stowasser and Hoffmann [13] studied KS orbitals to rationalize chemical phenomena. They showed that KS orbitals have the same order, symmetry and shape as orbitals using HF theory. They concluded that one may apply KS orbitals in a qualitative manner in MO arguments. We used concept of frontier orbitals from KS orbitals. Frontier orbitals (HOMO and LUMO) were calculated for the optimized structure of each molecule using DFT.

\section{Results and Discussion}

Optimized structures and frontier orbitals (HOMO and LUMO) of nucleotides (Figure 2), T705-RTP (Figure 3), GS-441524 triphosphate (Figure 4(a)) are shown. Results of related compounds with GS-441524 triphosphate (hydroxy GS-441524 triphosphate and dihydroxy GS-441524 triphosphate) are also shown (Figure 4(b) and Figure 4(c)). Colors of the atoms in the molecular models indicate as follows: gray, carbon; white, hydrogen; red, oxygen; blue, nitrogen; cyan, fluorine; and orange, phosphorus. According to the orbital phase, the lobe of a molecular orbital is indicated by green and red in HOMO and LUMO. In Figure 2, we see the HOMO and LUMO for ATP and GTP are localized in the purine group and those for CTP and UTP are localized in the pyrimidine group. However, each molecule has different HOMO and LUMO patterns. T-705RTP has HOMO and LUMO in the favipiravir structure (Figure 3). From here, we compare the shapes of electron clouds of HOMO and LUMO qualitatively. More quantitative methods are currently under study. We can see that the HOMO and LUMO patterns of T-705RTP are very similar to those of CTP. A shape similar to the three main lobes of HOMO of CTP appears in HOMO of T705-RTP. A 
form like LUMO of CTP, localized to four atoms (nitrogen atoms at positions 1 and 3 and carbon atoms at positions 4 and 6) in pyrimidine of CTP, is found in two carbon atoms and two nitrogen atoms in favipiravir structure of T705-RTP. As frontier orbitals are related to chemical reactivity [9], these results indicate that T-705RTP acts as a cytidine analogue in very early stage of interaction between ligand and receptor. Jin et al. evaluated the biochemical inhibition properties of T-705RTP and 2'-C-methyl-cytidine triphosphates (2CM-CTP) against

(a)<smiles>Nc1ncnc2c1ncn2[C@@H]1O[C@H](O)[C@@H](O)[C@@H](OP(=O)(O)OP(=O)(O)OP(=O)(O)O)[C@H]1C(F)(F)F</smiles>

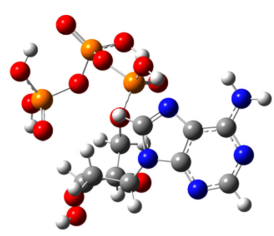

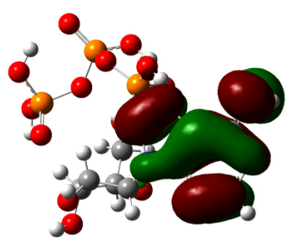

ATP (HOMO)

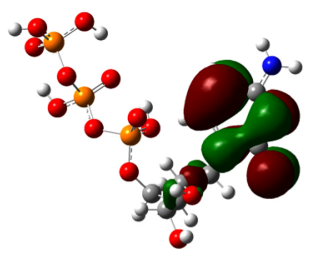

CTP (HOMO)

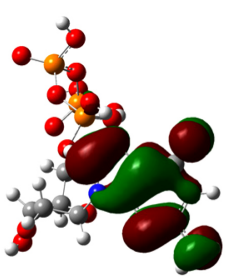

GTP (HOMO)

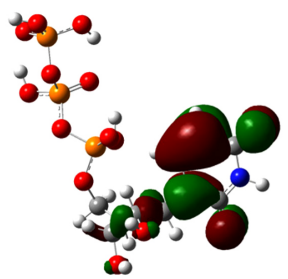

UTP (HOMO)

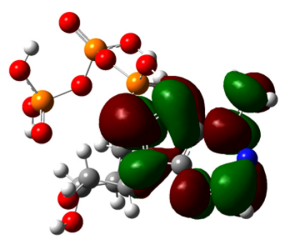

ATP (LUMO) (b)

(c)

(d)

UTP

GTP

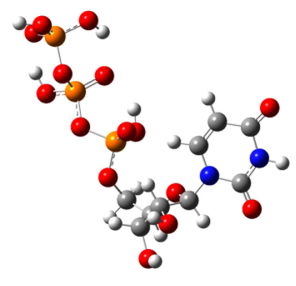

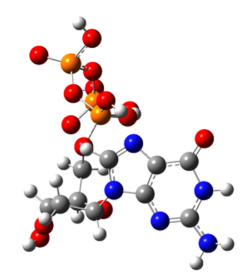

\begin{abstract}
UTP
\end{abstract}
Figure 2. Optimized structures and frontier orbitals (HOMO and LUMO) of nucleotides. (a) adenosine triphosphate (ATP) (b) cytidine triphosphate (CTP) (c) guanosine triphosphate (GTP) (d) uridine triphosphate (UTP).
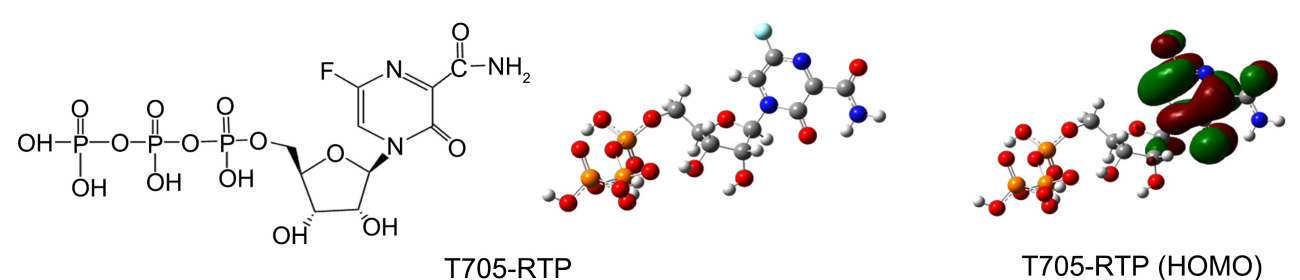

T705-RTP (HOMO)

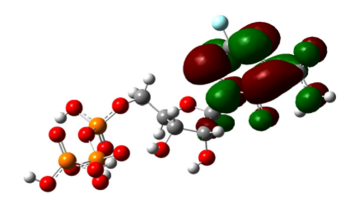

T705-RTP (LUMO)

Figure 3. Optimized structures and frontier orbitals (HOMO and LUMO) of T-705RTP. T-705RTP is the active triphosphate metabolite of T-705 (Favipiravir, Avigan ${ }^{\circledR}$ ) and has potent anti-influenza virus activity. 
(a)

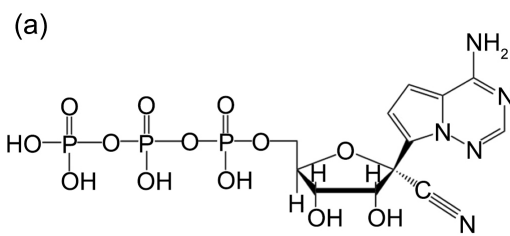

GS-441524 triphosphate (\#1)

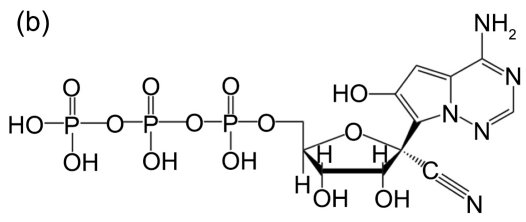

Hydroxy GS-441524-triphosphate (\#2)

(c)

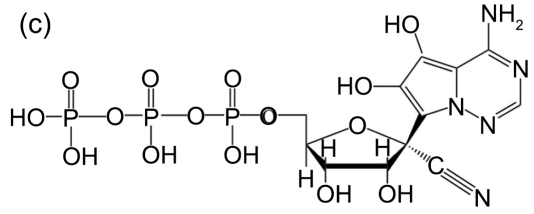

Dihydroxy GS-441524 triphosphate (\#3)

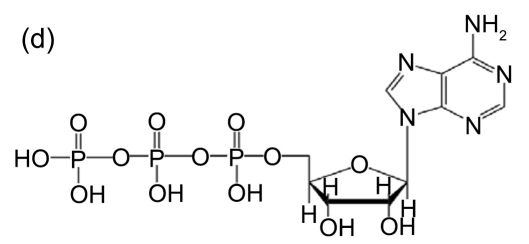

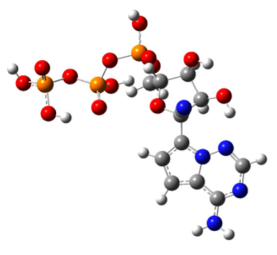

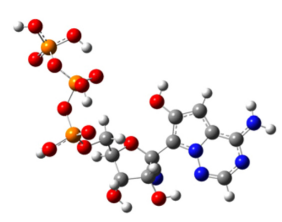

HOMO of \#1

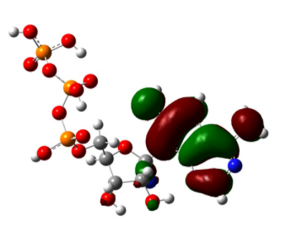

HOMO of \#2
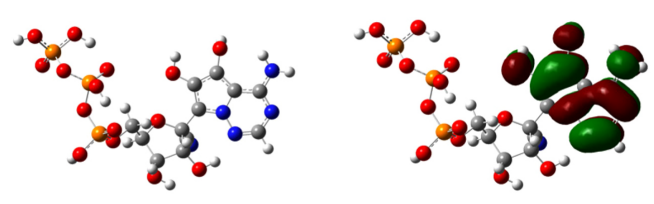

HOMO of \#3

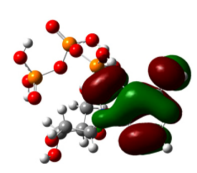

ATP (HOMO)

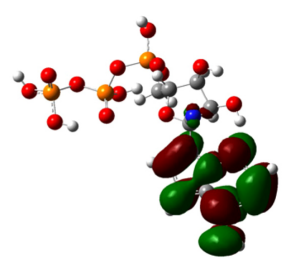

LUMO of \#1

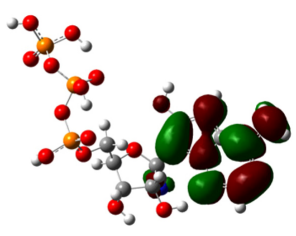

LUMO of \#2

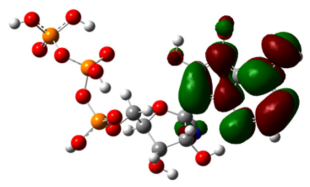

LUMO of \#3

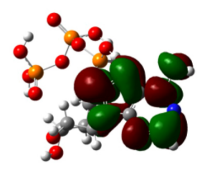

ATP (LUMO)

Figure 4. Optimized structures and frontier orbitals (HOMO and LUMO) of GS-441524 triphosphate and related compounds. GS-441524 triphosphate is the active triphosphate metabolite of remdesivir and has potent anti-virus activity. (a) GS-441524 triphosphate. (b) hydroxy GS-441524 triphosphate. (c) dihydroxy GS-441524 triphosphate. (d) HOMO and LUMO of ATP are shown for comparison.

human and mouse norovirus RNA polymerases [14]. It is known that the only two nucleoside analogs to inhibit norovirus replication were 2'-C-methyl-cytidine (2CM-C) and favipiravir (T-705), but their mechanism was unclear. They found that T-705RTP and 2CM-C triphosphate equally inhibited norovirus replication in human and mouse. 2CM-CTP inhibited the polymerases by competing directly with natural CTP during primer elongation, whereas T-705RTP competed mostly with ATP and GTP at the initiation and elongation steps. So, they suggested that 2CM-C inhibits replication of norovirus by acting as a cytidine analogue to terminate polymerization, while T-705 may inhibit the virus by multiple mechanisms. They suggested that T-705 RTP may be ambiguously recognized as a guanosine and adenosine analog leading to the inhibition of RNA synthesis. These experimental results do not match our theoretical results, which indicate T-705 RTP may be a cytidine analogue. Inhibition of RNA polymerization involves a complicated mechanism as not only electronic states, but also structural features are important. We think T-705RTP has both the electronic features of 
cytidine and the structural features of adenosine and guanosine. Remdesivir is effective against the Ebola virus disease [5]. Remdesivir converts to GS-441524 triphosphate which has potent anti-virus activity. GS-441524 triphosphate is recognized as an ATP analogue. The HOMO and LUMO of GS-441524 triphosphate are shown in Figure 4(a). For comparison, the HOMO and LUMO of ATP are shown in Figure 4(d). We can see the HOMO shape of GS-441524 triphosphate is dissimilar to that of ATP. We may see the LUMO of GS-441524 triphosphate contains HOMO shapes of CTP in the center. We know that active oxygen $\left(\mathrm{O}_{2}^{-}\right.$and $\left.\mathrm{NO}\right)$ production is elevated in inflamed tissues. High production of $\mathrm{O}_{2}^{-}$is most clearly observed in murine pneumonia caused by influenza $\mathrm{A}$ virus, Sendai virus and cytomegalovirus [15]. It is natural to assume that there is much active oxygen production in lungs with pneumonia by SARS-CoV-2. Active oxygen may oxidize GS-441524 triphosphate to add an $\mathrm{OH}$ group. We calculated hydroxy GS-441524 triphosphate and dihydroxy GS-441524 triphosphate. The HOMO and LUMO of hydroxy GS-441524 triphosphate and dihydroxy GS-441524 triphosphate are shown in Figure 4(b) and Figure 4(c), respectively. The HOMO of hydroxy GS-441524 triphosphate is a little similar to that of ATP, whereas the HOMO of dihydroxy GS-441524 triphosphate is very similar to that of ATP. The LUMO of both hydroxy GS-441524 triphosphate and dihydroxy GS-441524 triphosphate have almost the same shape as that of GS-441524 triphosphate. The resulting frontier orbital patterns indicate that dihydro GS-441524 triphosphate is the most suitable ATP analogue. Research for a new drug, which converts directly to dihydro GS-441524 triphosphate, should be conducted as soon as possible.

\section{Acknowledgements}

We acknowledge all the medical professionals fighting on the front lines of defense against COVID-19.

\section{Conflicts of Interest}

The author declares no conflicts of interest regarding the publication of this paper.

\section{References}

[1] Wu, F., Zhao, S., Yu, B., Chen, Y., Wang, W., Song, Z., Hu, Y., Tao, Z., Tian, J., Pei, Y., Yuan, M., Zhang, Y., Dai, F., Liu, Y., Wang, Q., Zheng, J., Xu, L., Holmes, E.C. and Zhang, Y. (2020) A New Coronavirus Associated with Human Respiratory Disease in China. Nature, 579, 265-269. https://doi.org/10.1038/s41586-020-2008-3

[2] Gao, Y., Yan, L., Huang, Y., Liu, F., Zhao, Y., Cao, L., Wang, T., Sun, Q., Ming, Z., Zhang, L., Ge, J., Zheng, L., Zhang, Y., Wang, H., Zhu, Y., Zhu, C., Hu, T., Hua, T., Zhang, B., Yang, X., Li, J., Yang, H., Liu, Z., Xu, W., Guddat, L.W., Wang, Q., Lou, Z. and Rao, Z. (2020) Structure of the RNA-Dependent RNA Polymerase from COVID-19 Virus. Science, eabb7498. https://doi.org/10.1126/science.abb7498

[3] Shiraki, K. and Daikoku, T. (2020) Favipiravir, an Anti-Influenza Drug against 
Life-Threatening RNA Virus Infections. Pharmacology \& Therapeutics, 209, Article ID: 107512. https://doi.org/10.1016/j.pharmthera.2020.107512

[4] Furuta, Y., Takahashi, K., Kuno-Maekawa, M., Sangawa, H., Uehara, S., Kozaki, K., Nomura, N., Egawa, H. and Shiraki, K. (2005) Mechanism of Action of T-705 against Influenza Virus. Antimicrobial Agents and Chemotherapy, 49, 981-986. https://doi.org/10.1128/AAC.49.3.981-986.2005

[5] Warren, T.K., Jordan, R., Lo, M.K., Ray, A.S., Mackman, R.L., Soloveva, V., Siegel, D., Perron, M., Bannister, R., Hui, H.C., Larson, N., Strickley, R., Wells, J., Stuthman1, K.S., Van Tongeren1, S.A., Garza, N.L., Donnelly, G., Shurtleff, A.C., Retterer, C.J., Gharaibeh, D., Zamani, R., Kenny, T., Eaton1, B.P., Grimes, E., Welch, L.S., Gomba, L., Wilhelmsen, C.L., Nichols, D.K., Nuss, J.E., Nagle, E.R., Kugelman, J.R., Palacios, G., Doerffler, E., Neville, S., Carra, E., Clarke, M.O., Zhang, L., Lew, W., Ross, B., Wang, Q., Chun, K., Wolfe, L., Babusis, D., Park, Y., Stray, K.M., Trancheva, I., Feng, J.Y., Barauskas, O., Xu, Y., Wong, P., Braun, M.R., Flint, M., McMullan, L.K., Chen, S., Fearns, R., Swaminathan, S., Mayers, D.L., Spiropoulou, C.F., Lee, W.A., Nichol, S.T., Cihlar, T. and Bavari, S. (2016) Therapeutic Efficacy of the Small Molecule GS-5734 against Ebola Virus in Rhesus Monkeys. Nature, 531, 381-385. https://doi.org/10.1038/nature17180

[6] Cai, Q., Yang, M., Liu, D., Chen, J., Shu, D., Xia, J., Liao, X., Gu, Y., Cai, Q., Yang, Y., Shen, C., Li, X., Peng, L., Huang, D., Zhang, J., Zhang, S., Wang, F., Liu, J., Chen, L., Chen, S., Wang, Zhang, Z., Cao, R., Zhong, W., Liu, Y. and Liu, L. (2020) Experimental Treatment with Favipiravir for COVID-19: An Open-Label Control Study. Engineering. (In Press) https://doi.org/10.1016/j.eng.2020.03.007

[7] Wang, M., Cao, R., Zhang, L., Yang, X., Liu, J., Xu, M., Shi, Z., Hu, Z., Zhong, W. and Xiao, G. (2020) Remdesivir and Chloroquine Effectively Inhibit the Recently Emerged Novel Coronavirus (2019-nCoV) in Vitro. Cell Research, 30, 269-271. https://doi.org/10.1038/s41422-020-0282-0

[8] Neogi, U., Hill, K.J., Ambikan, A.T., Heng, X., Quinn, T.P., Byrareddy, S.N., Sönnerborg, A., Sarafianos, S.G. and Singh, K. (2020) Feasibility of Known RNA Polymerase Inhibitors as Anti-SARS-CoV-2 Drugs. Pathogens, 9, 320-335. https://doi.org/10.3390/pathogens 9050320

[9] Fukui, K. and Fujimoto, H. (1997) Frontier Orbitals and Reaction Paths: Selected Papers of Kenichi Fukui. World Scientific Series in 20th Century Chemistry, Volume 7. World Scientific Publishing Co., Singapore. https://doi.org/10.1142/2731

[10] Mizukami, Y. (2004) Frontier Electron Density Pattern of Dioxin Congeners. Chemistry Letters, 33, 1328-1329. https://doi.org/10.1246/cl.2004.1328

[11] Mizukami, Y. (2015) Characters of Frontier Orbitals of Antiviral Drugs. Memoirs of the Faculty of Education, Shiga University (Natural Science), 64, 141-144. https://www.edu.shiga-u.ac.jp/ mizukami/papers/paper-2014-11-11.pdf

[12] Frisch, M.J., Trucks, G.W., Schlegel, H.B., Scuseria, G.E., Robb, M.A., Cheeseman, J.R., Scalmani, G., Barone, V., Mennucci, B., Petersson, G.A., Nakatsuji, H., Caricato, M., Li, X., Hratchian, H.P., Izmaylov, A.F., Bloino, J., Zheng, G., Sonnenberg, J.L., Hada, M., Ehara, M., Toyota, K., Fukuda, R., Hasegawa, J., Ishida, M., Nakajima, T., Honda, Y., Kitao, O., Nakai, H., Vreven, T., Montgomery Jr., J.A., Peralta, J.E., Ogliaro, F., Bearpark, M., Heyd, J.J., Brothers, E., Kudin, K.N., Staroverov, V.N., Kobayashi, R., Normand, J., Raghavachari, K., Rendell, A., Burant, J.C., Iyengar, S.S., Tomasi, J., Cossi, M., Rega, N., Millam, J.M., Klene, M., Knox, J.E., Cross, J.B., Bakken, V., Adamo, C., Jaramillo, J., Gomperts, R., Stratmann, R.E., Yazyev, O., Austin, A.J., Cammi, R., Pomelli, C., Ochterski, J.W., Martin, R.L., Morokuma, K., Zakrzewski, V.G., Voth, G.A., Salvador, P., Dannenberg, J.J., Dapprich, S., Da- 
niels, A.D., Farkas, O., Foresman, J.B., Ortiz, J.V., Cioslowski, J. and Fox, D.J. (2009) Gaussian 09, Revision A.02. Gaussian Inc., Wallingford.

[13] Stowasser, R. and Hoffmann, R. (1999) What Do the Kohn-Sham Orbitals and Eigenvalues Mean? Journal of the American Chemical Society, 121, 3414-3420. https://doi.org/10.1021/ja9826892

[14] Jin, Z., Tucker, K., Lin, X., Kao, C.C., Shaw, K., Tan, H., Symons, J., Behera, I., Rajwanshi, V.K., Dyatkina, N., Wang, G., Beigelman, L. and Deval, J. (2015) Biochemical Evaluation of the Inhibition Properties of Favipiravir and 2'-C-Methyl-Cytidine Triphosphates against Human and Mouse Norovirus RNA Polymerases. Antimicrobial Agents and Chemotherapy, 59, 7504-7516. https://doi.org/10.1128/AAC.01391-15

[15] Akaike, T. (2001) Role of Free Radicals in Viral Pathogenesis and Mutation. Reviews in Medical Virology, 11, 87-101. https://doi.org/10.1002/rmv.303 